\title{
Effect of Serotonin Depletion on Vibrissa-related Patterns of Thalamic Afferents in the Rat's Somatosensory Cortex
}

\author{
Carol A. Bennett-Clarke, Michael J. Leslie, Richard D. Lane, and Robert W. Rhoades \\ Department of Anatomy, Medical College of Ohio, Toledo, Ohio 43699
}

\begin{abstract}
To investigate the role of 5-HT in the development of the somatosensory cortex, this amine was depleted in newborn $(P-0)$ rats with a single subcutaneous injection of the toxin 5,7-dihydroxytryptamine (5,7-DHT) and thalamocortical organization was assayed by application of the carbocyanine dye $\mathrm{Di}-\mathrm{I}$ to the thalamocortical radiations or ventrobasal thalamus, or by staining cortical sections for AChE or cytochrome oxidase (CO). High-performance liquid chromatographic analysis of cortices from animals killed on P-6 or $P>60$ demonstrated that 5,7-DHT treatment resulted in 85.04 $\pm 12.6 \%$ and $72.5 \pm 1.5 \%$ reductions in cortical $5-\mathrm{HT}$, respectively. Alternate cortices from the brains of animals killed on P-6 processed for 5-HT immunoreactivity demonstrated a complete absence of the vibrissa-related pattern of immunoreactivity and only a small number of coarse immunoreactive axons. The $85 \%$ depletion of $5-\mathrm{HT}$ did not alter the somatotopic organization of thalamocortical afferents in animals killed on P-6 or P $>60$, but it did cause $30.5 \pm 7.3 \%$ and $19.1 \pm 3.7 \%$ reductions in the cross-sectional areas of the patches of thalamocortical afferents corresponding to the long mystacial vibrissae $(p<0.05)$. These reductions were not associated with significant reductions in either brain or cortical weight or with decreases in the dimensions of the thalamic representation of the vibrissa follicles. These results indicate that 5 -HT plays a significant role in the development of the thalamic innervation of the primary somatosensory cortex.
\end{abstract}

[Key words: 5-HT, barrels, Di-l, immunocytochemistry, AChE, 5,7-dihydroxytryptamine]

The dominant view regarding somatosensory cortical development is that it depends primarily upon information from sensory epithelia conveyed to cortex via thalamic axons (e.g., Van der Loos and Dorfl, 1978; Killackey et al., 1990; Woolsey, 1990). However, considerable attention is now being paid to the possibility that "non-lemniscal" corticipetal projections and elements intrinsic to the cortex may strongly influence this process (Fujimiya et al., 1986; D'Amato et al., 1987; Steindler et al., 1989; Ghosh et al., 1990; Rhoades et al., 1990; Blue et al., 1991). Perhaps the most robust "non-lemniscal" marker of cortical organization demonstrated so far is the dense 5-HT immunoreactivity that demarcates the representation of the body

\footnotetext{
Received Feb. 25, 1994; revised May 26, 1994; accepted June 8, 1994

This work was supported in part by EY08661 and DE07734. Thanks to Beth Figley, Mike Munson, and Dawn Allan for excellent technical assistance.

Correspondence should be addressed to Carol A. Bennett-Clarke, Department of Anatomy, Medical College of Ohio, CS\# 10008, Toledo, OH 43699.

Copyright (C) 1994 Society for Neuroscience 0270-6474/94/147594-14\$05.00/0
}

surface within S-I of all rodents examined to date (Fujimiya et al., 1986; D'Amato et al., 1987; Rhoades et al., 1990; BennettClarke et al., 1991). Serotoninergic axons are among the earliest afferents to the developing cortex (Lidov and Molliver, 1982) and a number of studies (e.g., Lauder and Krebs, 1978; Lauder, 1983) have suggested a variety of roles for 5 -HT in neural development. However, the results of two experiments have indicated that perinatal depletion of 5-HT has no long-term effect upon the somatotopic clustering of either thalamocortical axons or lamina IV cells (Daugherty and Haring, 1989; Blue et al., 1991). These results might prompt the conclusion that the transient and somatotopically patterned distribution of 5-HT within S-I plays no significant role in the development of this cortical area. However, interpretation of the results from these important initial experiments is limited by several potential methodological shortcomings. Blue et al. (1991) did not quantify the degree to which their manipulation [administration of $p$-chloroamphetamine (PCA)] depleted 5-HT from the developing cortex, nor did they provide any quantitative information regarding the organization of thalamocortical afferents. The aim of the present study was to extend the work of Blue et al. (1991) by using 5,7-dihydroxytryptamine to achieve greater depletions of 5-HT from the developing cortex and quantifying the effects of this manipulation upon both cortical amine levels and the organization of thalamocortical afferents.

\section{Materials and Methods}

Neonatal administration of 5,7-DHT. Pups ( $<3 \mathrm{hr}$ of age) were pretreated with desmethylimipramine [DMI, $25 \mathrm{mg} / \mathrm{kg}$ delivered intraperitoneally; this drug protects the noradrenergic (NE) fibers from the effects of the 5,7-DHT injection] and injected subcutaneously with $100 \mathrm{mg} / \mathrm{kg}$ of 5,7-DHT. Control animals were injected with the same volume of sterile physiological saline.

Assessment of brain and cortical weights. Whole brain and cortical weights were determined for all animals. Immediately after sacrifice [for animals whose brains were used for high performance liquid chromatography (HPLC)] or after perfusion (for all other rats), the brain was weighed. When cortices were dissected from the rest of the brain, these were also weighed.

Assessment of cortical 5-HT depletion. Both immunocytochemistry and HPLC were used to assess the effects of neonatal 5,7-DHT treatment upon cortical 5-HT concentrations. In all animals that provided anatomical results with respect to the organization of thalamocortical afferents, one hemisphere was used for immunocytochemical or HPLC analysis. Additional animals were employed to correlate HPLC and immunocytochemical results (Table 1).

Animals in which one hemisphere was used for HPLC (see below) were anesthetized with ether and quickly decapitated, and the brain was removed. The cerebral cortex employed for HPLC was dissected on an ice-cold surface. It was quickly weighed, frozen in dry ice and stored at $-70^{\circ} \mathrm{C}$ until needed. The frozen tissue samples were placed in a cold extraction solution composed of $0.4 N$ perchloric acid, 3 mM EDTA, and $0.23 \mathrm{~mm}$ ascorbic acid. Deoxyepinephrine hydrochloride (DEP) at 

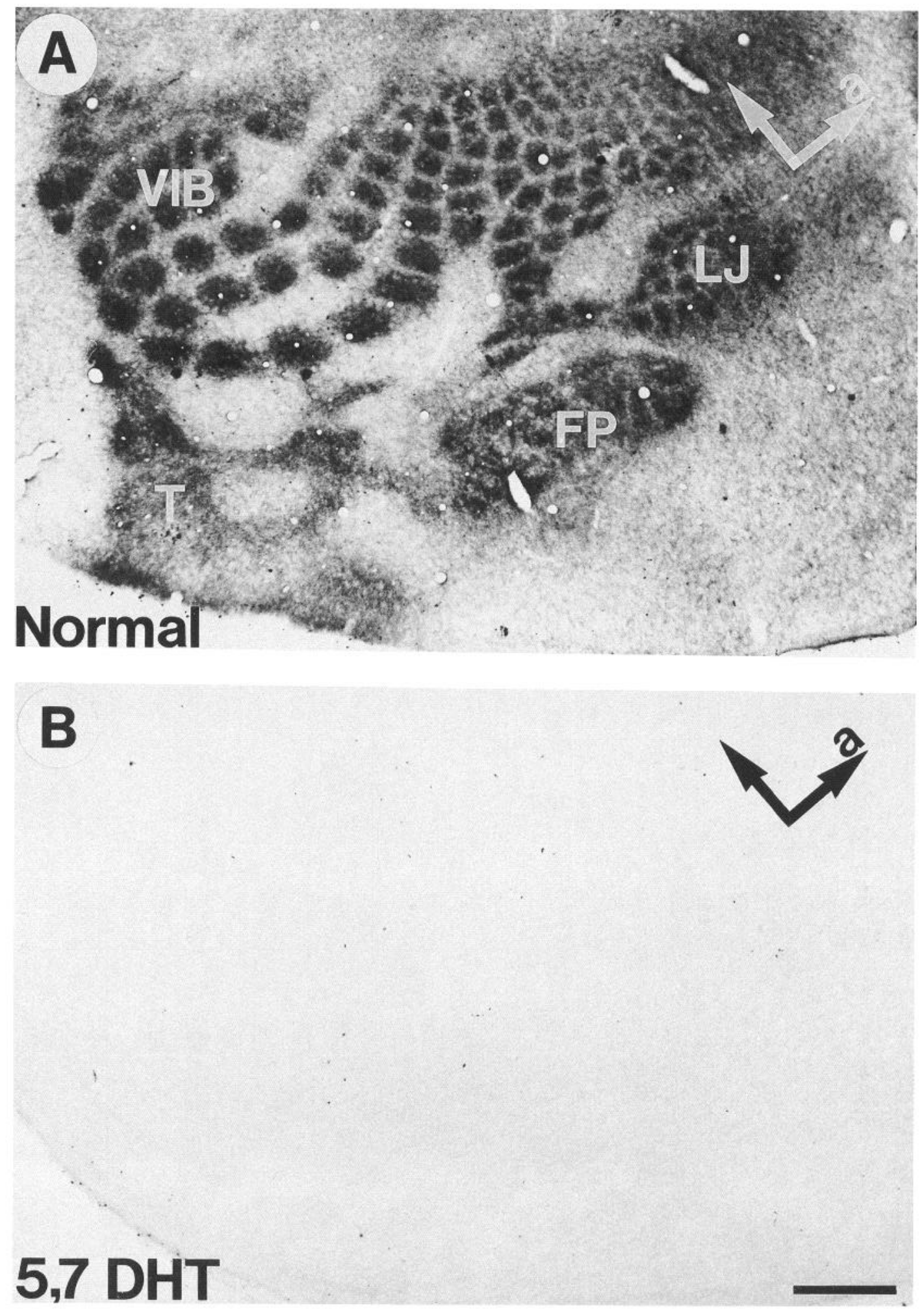

Figure 1. Effect of treatment with 5,7-DHT at birth upon the patterning of 5-HT immunoreactivity in the primary somatosensory cortex. $A$ shows the normal pattern of 5-HT-immunoreactive axons in a tangential section through the flattened cortex of a normal rat killed on P-6. $B$ is a similar section showing the lack of such immunoreactivity in a rat that received a subcutaneous injection of 5,7-DHT on P-0 and was killed on P-6. The arrows point toward anterior $(a)$ and lateral. $F P$, forepaw; $L J$, lower jaw; $T$, trunk; $V I B$, vibrissae. Scale bar, $500 \mu \mathrm{m}$.

a concentration of $5 \mathrm{ng} / \mathrm{ml}$ was included as an internal standard. To compensate for variations in sample size, the extraction solution was added to each sample at a concentration of $10 \mu \mathrm{l} / \mathrm{mg}$ sample weight. Each mixture was homogenized in an ice bath with a VirSonic Ultrasonic 300 Cell Disrupter fitted with a titanium microprobe tip operated at 16
$\mathrm{W}$ for $20 \mathrm{sec}$. The samples were then centrifuged at $20,000 \times \mathrm{g}$ for 15 $\min$ at $4^{\circ} \mathrm{C}$. The supernatants were removed and stored in the dark on ice until a $20 \mu \mathrm{l}$ aliquot of each sample was injected onto a Waters $\mu$ Bondapak $\mathrm{C}_{18}(3.9 \times 150 \mathrm{~mm})$ column.

Detection and quantitation of 5-HT in the column eluent were per- 
Table 1. 5,7-DHT treatment and assessment of cortical 5-HT concentration

\begin{tabular}{llll}
$\begin{array}{l}\text { Age } \\
\text { killed }\end{array}$ & $\begin{array}{l}5,7- \\
\text { DHT } \\
\text { treated }\end{array}$ & $\begin{array}{l}\text { Num- } \\
\text { ber of } \\
\text { animals }\end{array}$ & Tissue processing \\
\hline P-6 & + & 27 & HPLC for 5-HT/Di-I radiations \\
& - & 15 & \\
P-6 & + & 9 & HPLC for 5-HT/5-HT ICC \\
& - & 5 & \\
P-6 & + & 13 & Di-I radiations/5-HT ICC \\
& - & 8 & \\
P-6 & + & 7 & HPLC for 5-HT \& NE \\
& - & 4 & \\
P-6 & + & 7 & Di-I in VPM/5-HT ICC \\
& - & 4 & \\
P-6 & + & 3 & \\
& - & 2 & 5-HT ICC/D $\beta$ H ICC \\
P-6 & + & 11 & AChE histochemistry/5-HT ICC \\
& - & 9 & \\
P-60 & + & 9 & CO histochemistry/HPLC for 5-HT \\
& - & 7 & \\
P-60 & + & 3 & HPLC for 5-HT \& NE \\
& - & 3 &
\end{tabular}

ICC, immunocytochemistry.

formed with a Waters model 464 electrochemical detector using a glassy carbon electrode at a potential of $600 \mathrm{mV}$. The output from the detector was plotted and measured using a Water's Baseline 810 chromatography workstation. Before injecting the samples, the instrument was equilibrated by running the mobile phase $\left(50 \mathrm{mM} \mathrm{NaH}_{2} \mathrm{PO}_{4}, 50 \mathrm{mg} /\right.$ liter sodium octyl sulfate, $20 \mathrm{mg} /$ liter EDTA, and $15 \%$ methanol at $\mathrm{pH} 4.0$ ) through the column at $1 \mathrm{ml} / \mathrm{min}$ for several hours. The instrument was calibrated by running 5 -HT standards $(1-200 \mathrm{ng} / \mathrm{ml})$ through the system to determine the standard curve (ratio of 5-HT peak area to concentration). For detection of norepinephrine (NE), the mobile phase composition was changed to $70 \mathrm{mM} \mathrm{NaH} \mathrm{NO}_{4}, 200 \mathrm{mg}$ /liter sodium octyl sulfate, $90 \mathrm{mg} /$ liter EDTA, and $6 \%$ acetonitrile at $\mathrm{pH} 4.55$.

The chromatographic peaks of the samples were quantified by peakarea measurements and compared to the peak-area curve of the standards. To verify the identity of the 5-HT peak, the retention times of the peak found in the samples with the peak given by the standard were compared. In addition, on several occasions reagent 5-HT was added to previously run samples. In these experiments, a single appropriately enlarged peak with a retention time identical to that of the 5-HT from the standard solution was always observed. Similar methods were employed in a small number brains to determine the effects of neonatal 5,7-DHT administration on the cortical concentration of NE.

Processing of brains for immunocytochemistry followed the procedures described by Rhoades et al. (1990). In animals also used for HPLC, the portion of the brain used for immunocytochemistry was fixed by immersion in $4 \%$ paraformaldehyde for $2-4 \mathrm{~d}$ before processing. Other animals were anesthetized with ether and perfused transcardially with $0.9 \%$ saline in $0.1 \mathrm{~m}$ sodium phosphate buffer (PBS, $\mathrm{pH}=7.4,21^{\circ} \mathrm{C}$ ). This was followed by a fixative consisting of $4.0 \%$ paraformaldehyde in the same buffer $\left(4^{\circ} \mathrm{C}\right)$. Brains were removed and postfixed for $12-36$ $\mathrm{hr}$. Sections $(50 \mu \mathrm{m})$ cut through the flattened cortex were incubated in primary antibody (5-HT INCSTAR, 1:1500 dilution in phosphate buffer) for $14-20 \mathrm{hr}$ at room temperature, rinsed with phosphate buffer, incubated for 1 hour in goat anti-rabbit IgG diluted 1:200, rinsed again, and incubated in $\mathrm{AB}$ complex (Vectastain) diluted 1:100. Following several rinses, sections were reacted with $0.05 \%$ 3, $3^{\prime}$-diaminobenzidine (DAB) and $0.015 \%$ hydrogen peroxide in $0.1 \mathrm{M}$ phosphate buffer. After several rinses in phosphate buffer, sections were plated on gelatin-coated slides, air dried, dehydrated in graded ethanols, cleared with xylene, and coverslipped with Permount.

In a small number of animals, alternate sections were immunostained using a primary antibody generated against dopamine $\beta$-hydroxylase
A

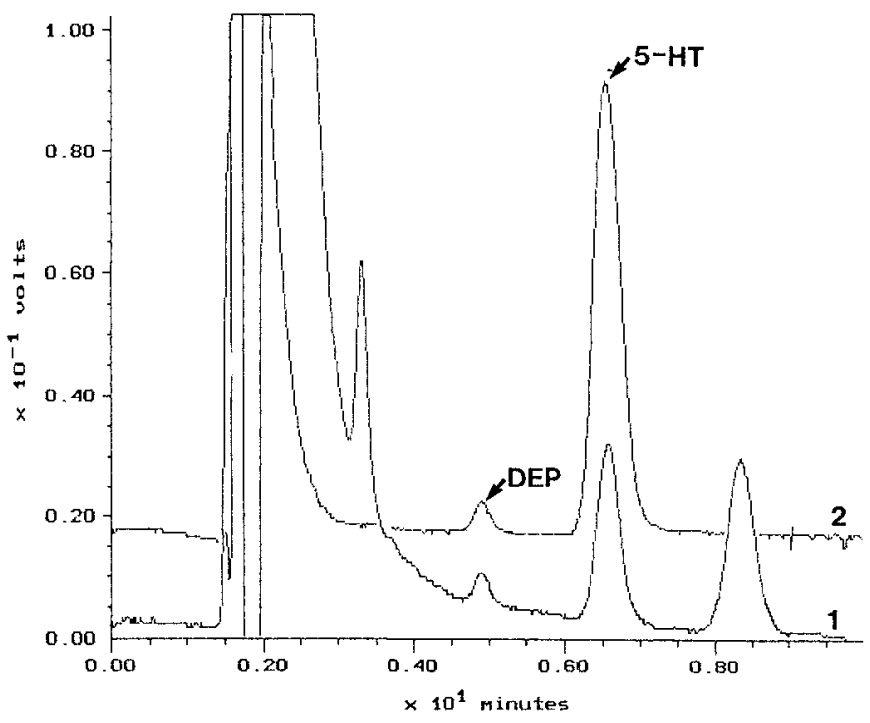

B

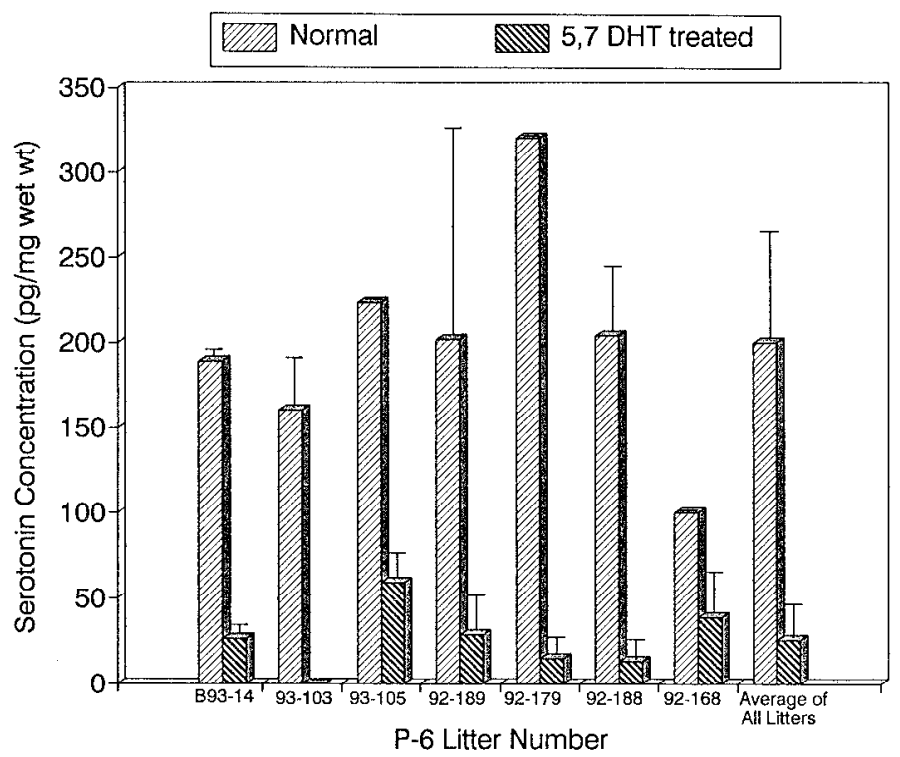

Figure 2. A shows HPLC chromatograms for 5-HT generated using an electrochemical detector. Profile 2 is for a standard sample spiked with $50 \mathrm{ng} / \mathrm{ml}$ of $5-\mathrm{HT}$; the smaller peak at $4.9 \mathrm{~min}$ is DEP; the large peak with an elution time of $6.6 \mathrm{~min}$ is 5 -HT. Profile 1 is for the biogenic amines present in the S-I cortex of a P-6 rat; note the 5-HT peak at 6.6 min, which corresponds exactly with the standard. $B$ is a bar graph showing the concentrations of 5-HT (mean + SD) in the cortices of rats treated with subcutaneous injections of 5,7-DHT on the day of birth and littermate controls. All animals were killed on P-6. Data from seven different litters are presented along with the averaged results from all litters.

$(\mathrm{D} \beta \mathrm{H})$ (Eugene Tech.) to visualize the noradrenergic terminals in S-I. The $\mathrm{D} \beta \mathrm{H}$ antibody was diluted 1:1000 and all subsequent steps of the immunostaining were as previously described.

Labeling thalamocortical afferents with $D i$-I. In most brains, thalamocortical fibers were labeled by application of Di-I directly to the thalamic radiations. Brains were postfixed for 2-7 $d$ and the cortex used for anterograde tracing was then dissected and weighed. Di-I $\left(1,1^{\prime}-\right.$ dioctadecyl-3,3,3",3'-tetramethylindocarbocyanine perchlorate; Molec- 

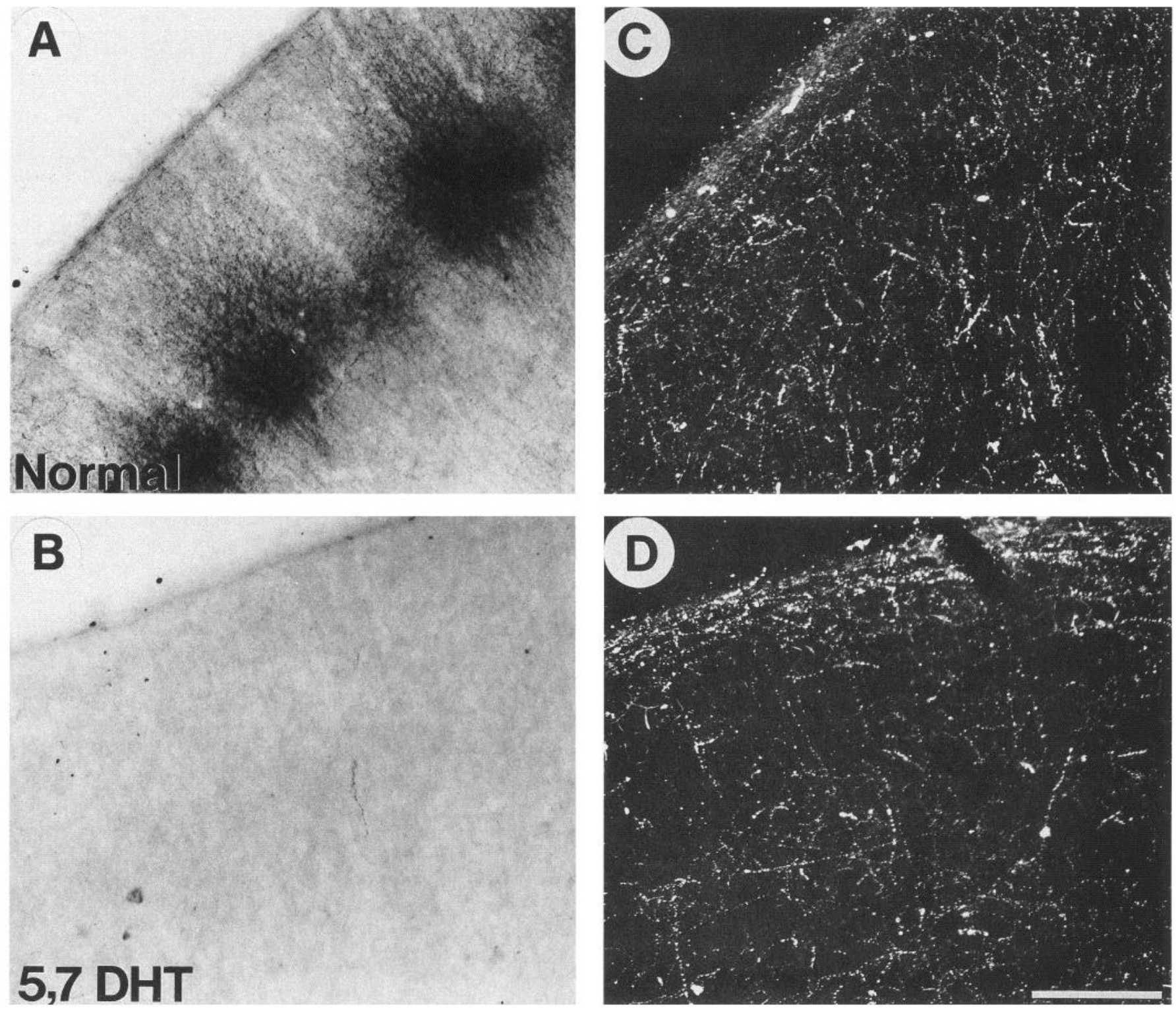

Figure 3. Photomicrographs demonstrating the effect of 5,7-DHT on levels of 5-HT and D $\beta$ H in the parietal cortex of P-6 rats. $A$ and $B$ show 5-HT immunoreactivity in coronal sections of normal and 5,7-DHT-treated littermates. $C$ and $D$ are dark-field photomicrographs that show D $\beta \mathrm{H}$ immunoreactivity from the same pair of animals. Note the loss of the dense aggregates of 5-HT-immunoreactive fibers in the 5,7-DHT-treated rat and the lack of effect upon the density of $\mathrm{D} \beta \mathrm{H}$-immunoreactive fibers. Scale bar, $250 \mu \mathrm{m}$.

ular Probes) was dissolved in 10\% dimethylformamide and painted onto the thalamic radiations. After the deposits were completed, the brains were placed in fixative and warmed in a $37^{\circ} \mathrm{C}$ oven for $4-6 \mathrm{~d}$ and then stored in the dark for 2 weeks to 2 months. Cortices were flattened and cut parallel to the pial surface $(50-\mu \mathrm{m}$-thick sections) with a freezing microtome and collected in sodium phosphate buffer. Sections were cleared in iothalmate meglumine (Conray, Mallinckrodt) and then placed on a slide in small pools of $50 \%$ dextran (Sigma; molecular weight, 67.9 $\mathrm{kDa}$ ) and coverslipped.

In additional animals, thalamocortical fibers were labeled by placement of Di-I crystals into the ventral posteromedial thalamus. Here, crystals of the tracer were picked up with pipettes (20-30 $\mu \mathrm{m}$ tips) and inserted into the thalamus utilizing a dissecting microscope. These brains were then processed in the manner described above.

Labeling thalamocortical afferents by acetylcholinesterase (AChE) histochemistry. Histochemistry for AChE was also employed to label the terminals of thalamocortical afferents (Krist, 1979; Robertson et al., 1988). Cortices fixed in one of the two ways described above were flattened on a freezing microtome and cut into $50 \mu \mathrm{m}$ sections. Sections were then processed for the demonstration of $\mathrm{AChE}$ according to the method of Schlaggar et al. (1993).
Cytochrome oxidase $(\mathrm{CO})$ staining in the ventral posteromedial thalamus nucleus (VPM). Cytochrome oxidase was demonstrated in $50 \mu \mathrm{m}$ diencephalic sections following the protocol of Wong-Riley (1979). After the completion of this reaction, sections were rinsed, dehydrated in graded alcohols, cleared in xylene, and coverslipped.

Evaluation of long-term consequences of neonatal 5,7-DHT administration on cortical organization. The long-term effects of neonatal 5,7DHT administration upon the vibrissa representation in the primary somatosensory cortex were evaluated in a manner similar to that described above except that animals survived for at least $60 \mathrm{~d}$ after the neonatal 5,7-DHT injection and cortical patches corresponding to the vibrissae were identified by $\mathrm{CO}$ histochemistry rather than Di-I or AChE labeling.

Measurement of central representations of vibrissa follicles. Tissue in which Di-I was used to label thalamocortical fibers was evaluated as follows. Each tangential section in which patches of label corresponding the four most caudal vibrissa follicles in each row were visible was photographed and printed. These patches were selected for measurement because of their relatively large size and because they were heavily labeled in almost every normal and 5,7-DHT-treated animal. The patch areas were measured using a computerized planimeter. The individual 


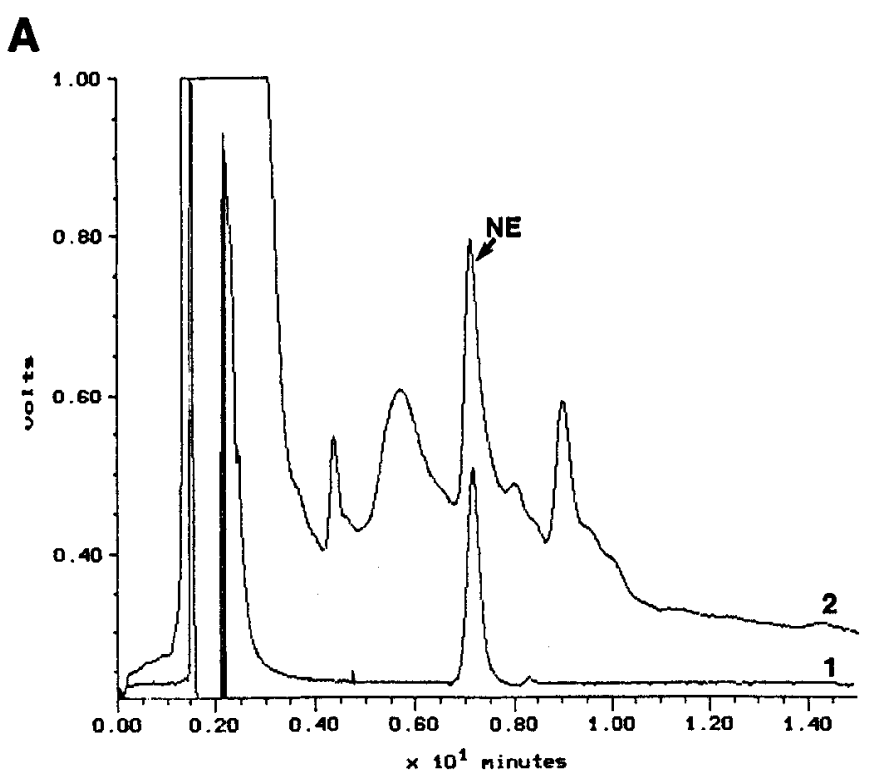

B
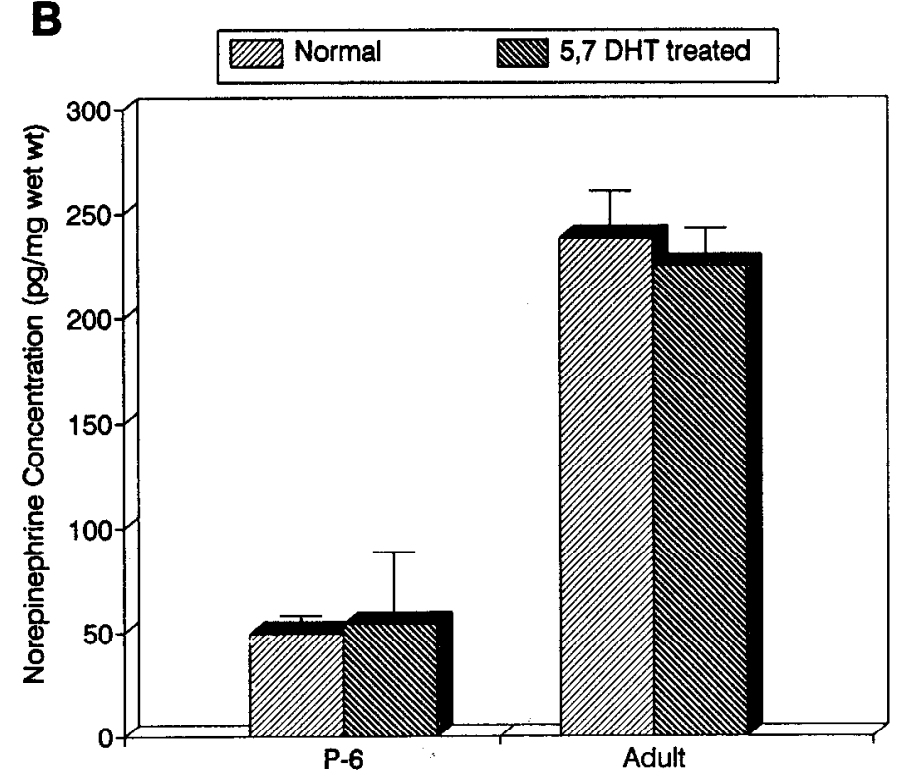

Figure 4. A shows representative HPLC chromatograms for NE. Profile 1 is for a standard sample containing $10 \mathrm{ng} / \mathrm{ml}$ of $\mathrm{NE}$; note the single peak at the elution time of $7.12 \mathrm{~min}$. Profile 2 is of the biogenic amines present in the S-I cortex of an adult animal. $B$ is a histogram showing the effects of neonatal 5,7-DHT injections in DMI-pretreated rats upon cortical concentrations on NE. Note the lack of effect in rats killed on P-6 or in adulthood.

who carried out most ( $>90 \%)$ of these measurements was blind as to the treatment of the animal. The largest measurement for each patch in a given cortex was used for analysis. When thalamocortical afferents were labelled by AChE histochemistry, patches were drawn using a microscope equipped with a drawing tube and measured in the manner described above. This approach was also used for measurement of $\mathrm{CO}$ stained patches in cortex and VPM. For statistical analysis, measurements from all patches in a given structure (cortex or VPM) were averaged so that each animal contributed a single value to the analysis. In an additional analysis designed to assess the validity of hand-drawing of patch borders, AChE-stained sections from six randomly selected normal and six 5,7-DHT-treated animals were analyzed in the following way. Each section was scanned with a computerized densitometer and the density of staining at the center of the patch representing the $\mathrm{C}-2$ vibrissa was measured and set as a threshold. The computer then used this threshold to establish the boundaries of the vibrissa-related patches. These patches were outlined and analyzed as described above and below.

Because of the findings obtained with respect to the size of the patches representing the mystacial vibrissae in the cortex (see Results), the distances between the centers of the patches of thalamocortical afferents was also evaluated. This was accomplished by placing a mark in the center of each of the above-described patches and drawing lines to connect all of the marks. The summed distances of these lines would then provide a relative estimate of the total cortical area devoted to the representation of the long caudal vibrissae.

Results from normal and 5,7-DHT-treated animals were compared by means of independent $t$ tests with $p<0.05$ as the accepted level of significance.

\section{Results}

\section{Effect of neonatal 5,7-DHT injection on the aminergic innervation of the cerebral cortex}

A single subcutaneous injection of 5,7-DHT on the day of birth resulted in a nearly $90 \%$ depletion of 5-HT in the cerebral cortex. The pattern of 5-HT immunoreactivity in the primary somatosensory cortex of a normal rat killed on P-6 is shown in Figure $1 A$ and that in a P-6 rat that sustained a neonatal 5,7-DHT injection is depicted in Figure $1 B$. The pattern observed in the normal rat is absent in the 5,7-DHT-treated animal. All of the animals used for the analysis of thalamocortical development in which one hemisphere was employed for immunocytochemistry had reductions in 5-HT immunoreactivity similar to that depicted in Figure $1 B$.

The results of the HPLC analysis confirmed those obtained with immunocytochemistry: subcutaneous injection of 5,7-DHT on the day of birth resulted in an average reduction (mean \pm SD) of $85.04 \pm 12.6 \%(p<0.05)$ in the concentration of 5-HT in the cortices of rats killed on P-6. Figure $2 A$ provides an example of a chromatogram demonstrating our ability to measure 5-HT levels using HPLC and Figure $2 B$ summarizes results from seven litters (all killed on P-6) in which littermates either received 5,7-DHT injections ( $N=36$ rats) or vehicle only $(N$ $=20$ rats). The effect of 5,7-DHT treatment was reasonably consistent across litters. The maximum reduction in 5-HT for a given litter was $100 \%$ (litter 93-103) and the minimum reduction was $61 \%$ (litter 92-168). Only animals in which the depletion of $5-\mathrm{HT}$ was $>85 \%$ were included in the analysis of cortical organization.

Whilc nconatal injection of 5,7-DHT significantly reduced the concentration of 5-HT in the developing cortex, it had no significant influence upon the apparent density of fibers recognized by an antibody directed against tyrosine hydroxylase (TH), a marker catecholaminergic axons. Figure 3 shows results from two littermates, one of which received a 5,7-DHT injection on the day of birth. Alternate sections from the two animals were processed for 5-HT or TH immunoreactivity. Treatment with 5,7-DHT resulted in a loss of the clustered 5-HT immunoreactivity (Fig. $3 C$ ), but no appreciable change in the density of $\mathrm{TH}$ positive fibers (Fig. $3 D$ ).

HPLC analysis (Fig. 4) demonstrated no significant changes in the concentration of NE in the cortices of 5,7-DHT-treated rats. Figure $4 A$ shows a chromatogram demonstrating our ability to measure NE, and Figure $4 B$ shows results from one litter of rats (four control and seven 5,7-DHT-treated animals) killed on P-6 and one litter (three control and three 5,7-DHT-treated animals) killed after they reached P-60. Neonatal administration of 5,7-DHT had no significant short- or long-term effects on the concentration of $\mathrm{NE}$ in the cerebral cortex. 

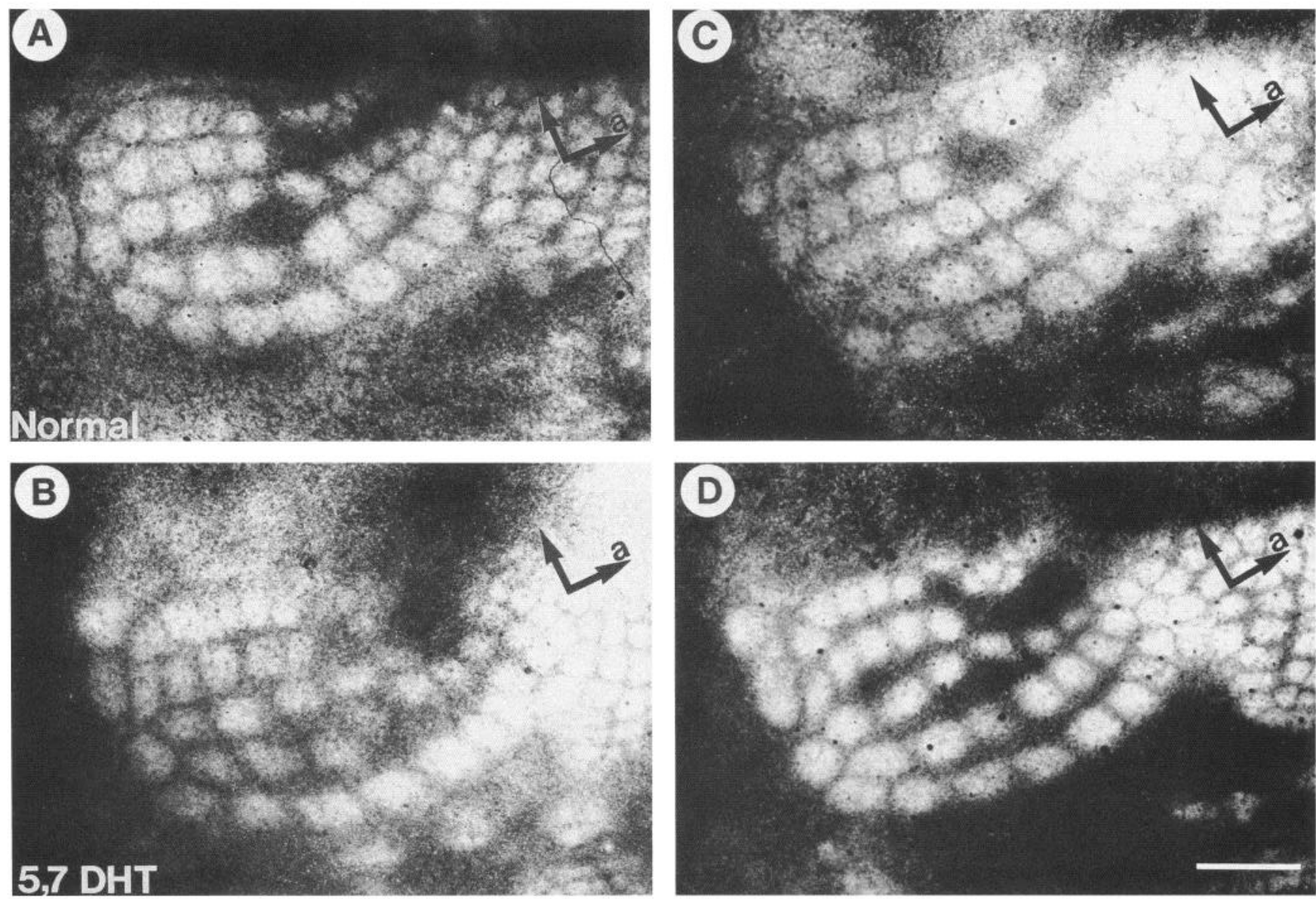

Figure 5. Low power episcopic fluorescence photomicrographs of tangential cortical sections from two normal P-6 rat ( $A$ and $C$ ) and two 5,7DHT treated littermates $(B$ and $D)$. In each case, Di-I was placed on the thalamic radiations to visualize thalamocortical axon arbors in lamina IV of S-I. Note the difference between the sizes of the Di-I-labeled patches in the normal and 5,7-DHT-treated animals. Thearrows point to anterior (a) and lateral. Scale bar, $500 \mu \mathrm{m}$.

\section{Effect of neonatal 5,7-DHT injection on the thalamic innervation of the primary somatosensory cortex}

Treatment with 5,7-DHT on the day of birth had no significant effect on the somatotopic patterning of thalamocortical afferents in rats killed on P-6 (Fig. 5). Thalamocortical fibers labeled with Di-I in both normal and manipulated animals were organized in clusters or patches that corresponded to the distribution of the mystacial vibrissae.

Neonatal treatment with 5,7-DHT did produce a quantitative change in the patterning of thalamocortical afferents. The patches or clusters in the neonatally manipulated rats (Fig. $5 B, D$ ) were consistently smaller than those in the normal animals (Fig. $5 A, C)$.

Figure 6 shows the areas of patches of Di-I-labeled thalamocortical axons measured in three separate litters with all animals killed on P-6. Each pair of bars in each panel provides the mean cross-sectional area $( \pm \mathrm{SD})$ for the patches of thalamocortical axons corresponding to the four most caudal vibrissae in each row. Note first that the patches of thalamocortical afferents corresponding to ventral row (D and E) vibrissa follicles are larger than those corresponding to more dorsal row follicles (A and $\mathrm{B}$ ) and that the reduction in patch size in the 5,7-DHT-treated animals is approximately the same for all rows. Overall, neonatal 5,7-DHT treatment resulted in a $33.7 \pm 4.7 \%$ reduction for all patches of thalamocortical afferents corresponding to the large mystacial vibrissa follicles. The average cross-sectional area of the cortical patches representing these follicles in the normal animals was $0.0937 \pm 0.011 \mathrm{~mm}^{2}$. That for the same patches in the 5,7-DHT-treated animals was 0.0579 $\pm 0.005 \mathrm{~mm}^{2}(p<0.05)$. Patches corresponding to A-row follicles were decreased in area by $38.1 \%$, B-row patches were decreased by $36.9 \%$, C-row patches by $28.02 \%$, D-row patches by $33.2 \%$, and E-row patches by $34.3 \%$. All of these decreases were statistically significant $(p<0.05)$.

The measurements described in the preceding paragraphs were obtained from animals in which Di-I was applied to the thalamic radiations after the cortex had been dissected from the rest of the brain. It is possible that raphe axons passing into the cortex from its rostral pole may have been labeled in these preparations. If this were the case, the reduction in the patch size in the 5,7-DHT-treated animals may have simply reflected the loss of the 5-HT axons that are codistributed with thalamocortical afferents for the first 2 weeks of life. Two control experiments were carried out to address this issue.

In one group of rats (four normal and seven 5,7-DHT-treated animals) killed on P-6, Di-I crystals were placed in the ventrobasal thalamus to label the terminals of thalamocortical fibers (Fig. 7). The average cross-sectional area for the patches corresponding to the long mystacial vibrissae in the normal rats 

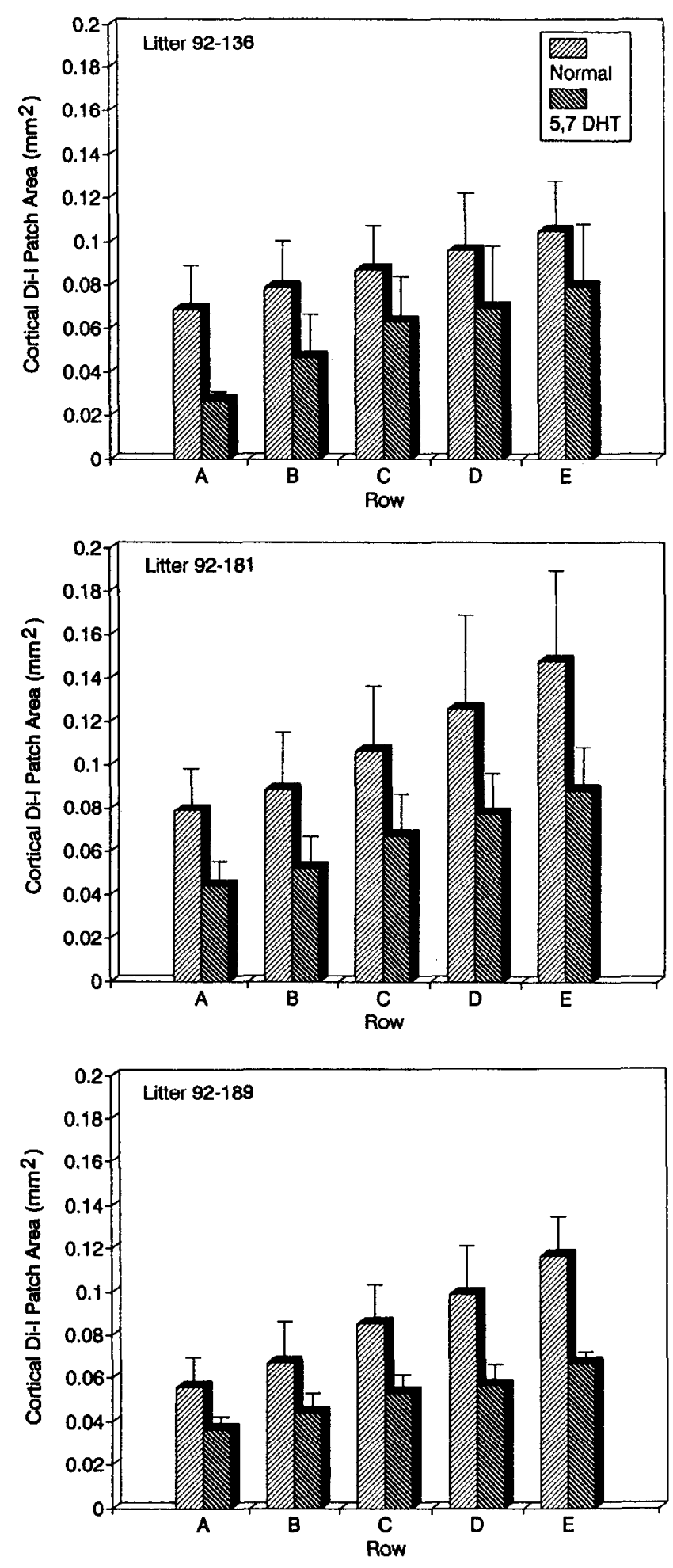

Figure 6. Three histograms each representing the areas of patches of thalamocortical axon arbors measured in lamina IV of the cortices of litters of animals that were killed on P-6. Half of the animals in each litter received a subcutaneous injection of 5,7-DHT on the day of birth and the remaining animals were controls. Each bar represents the mean $(+\mathrm{SD})$ for all the patches in a given row for all of the normal or 5,7DHT-treated animals in a litter. The differences between the results from the normal and experimental animals from each litter are statistically significant $(p<0.05)$. was $0.0628 \pm 0.008 \mathrm{~mm}^{2}$ and that for the $5,7-\mathrm{DHT}$-treated animals was $0.0489 \pm 0.003 \mathrm{~mm}^{2}(p<0.05)$.

In a second group of rats ( 9 normal and $115,7-\mathrm{DHT}$-treated animals), staining for AChE (Fig. 8) was employed to label the terminals of thalamocortical axons (Krisst, 1979; Robertson et al., 1988; Schlaggar et al., 1993). The average size of the cortical patches corresponding to the long mystacial vibrissae in the normal animals was $0.0410 \pm 0.002 \mathrm{~mm}^{2}$ and that for the 5,7DHT-treated animals was $0.02899 \pm 0.002 \mathrm{~mm}^{2}(p<0.05)$.

The results from these two groups of animals indicate that the reduced area of the patches of Di-I labeling in the 5,7-DHTtreated rats in which tracer was applied to the thalamic radiations was not the result of the "subtraction" or raphe-cortical axons present in the normal animals.

The results obtained with the computer-assisted analysis of AChE-stained sections from normal and 5,7-DHT-treated animals provided results consistent with those described above. The average patch size in the normal animals was $0.043 \pm 0.01$ $\mathrm{mm}^{2}$ and that for the 5,7-DHT-treated animals was $0.031 \pm$ $0.01 \mathrm{~mm}^{2}$. Thus, the average reduction in patch size for the $5,7-$ DHT animals was $28 \%$, a value very similar to the $29 \%$ obtained in the by-hand measurements.

\section{Effects of neonatal 5,7-DHT treatment on brain and cortical weight}

Analysis of brain and cortical weights of the animals that contributed to analysis described immediately above indicated that neonatal 5,7-DHT treatment had no significant effect upon either of these measures (Fig. 9). The average brain weight (Fig. $9 \mathrm{~A}$ ) for the normal animals (mean $\pm \mathrm{SD}$ ) was $0.604 \pm 0.062$ $\mathrm{gm}$ and that for the treated rats was $0.589 \pm 0.070 \mathrm{gm}(p>$ 0.05 ). The average cortical weight (Fig. $9 B$ ) for the normal animals was $0.138 \pm 0.042 \mathrm{gm}$ and that for the treated rats was $0.140 \pm 0.038 \mathrm{gm}(p>0.05)$. It is important to note that all of the 5,7-DHT-treated animals from the litters included in this analysis had significant reductions in the cortical 5-HT (see Fig. 2).

\section{Effects of neonatal 5,7-DHT treatment on the thalamic vibrissa representation}

The developing ventrobasal complex is not heavily innervated by 5 -HT-containing axons (Fig. 10C) and neonatal administration of 5,7-DHT has no substantial effect upon the density of this innervation (Fig. 10D). There was also no effect of neonatal 5,7-DHT treatment upon the average cross-sectional area of the CO-reactive patches representing the vibrissa follicles (compare Fig. 10 $A, B$ ). The average size of the CO-reactive patches corresponding to the four most caudal vibrissa follicles in each row in normal rats killed on P-6 was $0.00569 \pm 0.0005 \mathrm{~mm}^{2}$ and that for the same follicles in neonatally treated rats killed on P-6 was $0.00543 \pm 0.0005 \mathrm{~mm}^{2}(p>0.05)$.

\section{Long-term effects of neonatal 5,7-HT treatment upon the organization of the primary somatosensory cortex}

The 5,7-DHT-induced change in cortical organization was maintained into adulthood. We used $\mathrm{CO}$ staining to visualize the patches corresponding to the mystacial vibrissae in adult rats (Fig. $11 A, B$ ). The average cross-sectional area of the cortical patches representing the large mystacial vibrissae in the normal animals was $0.1295 \pm 0.0131 \mathrm{~mm}^{2}$. That for exactly the same patches in the 5,7-DHT-treated animals was $0.1045 \pm 0.0122$ 

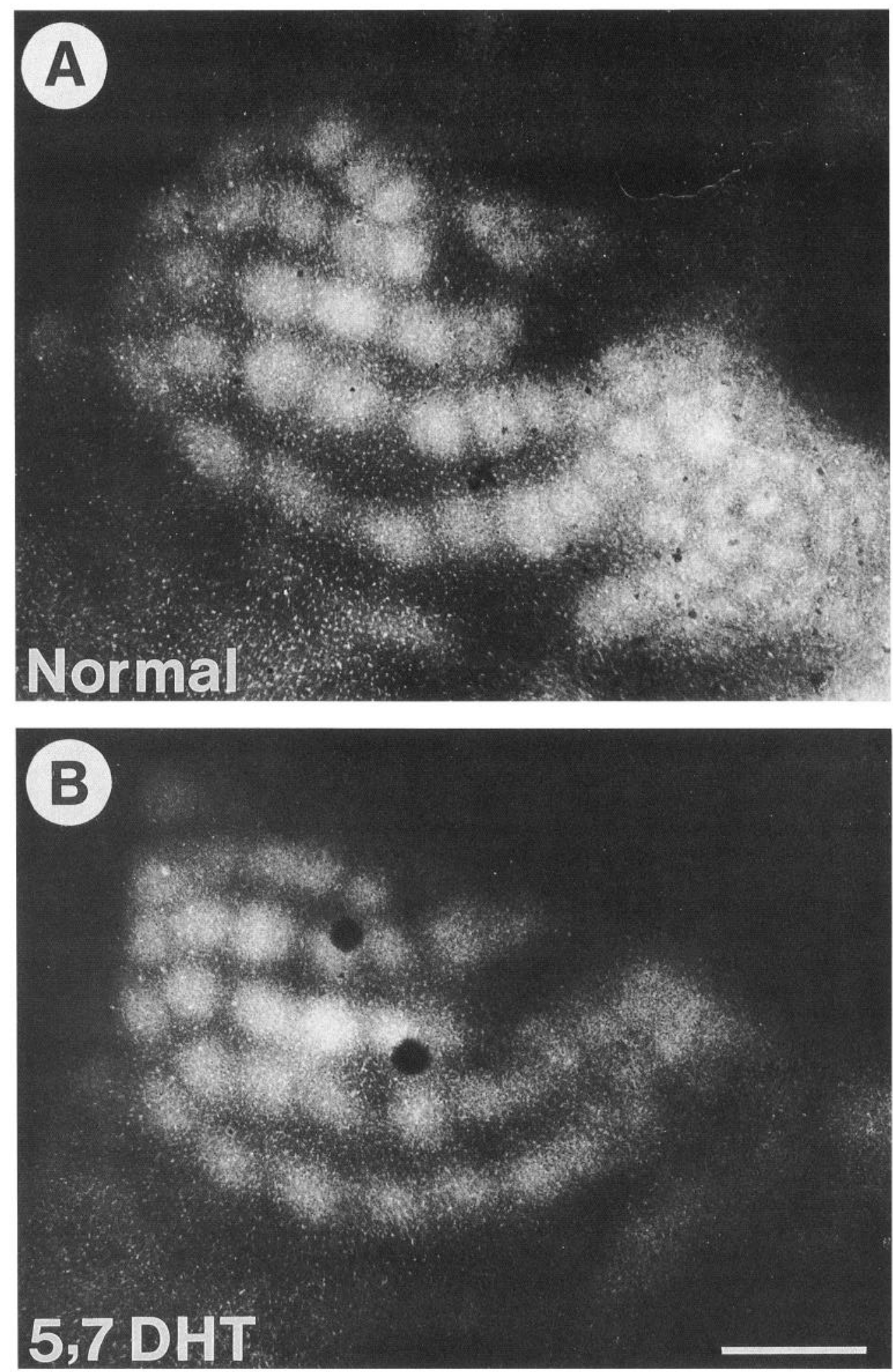

Figure 7. Low-power episcopic fluorescence photomicrographs of tangential cortical section from a normal $(A)$ and 5,7-DHT-treated littermate $(B)$ killed on P-6. In each case, Di-I was placed in the ventral posterior thalamus to visualize the thalamocortical axon arbors in layer IV of S-I. Note the differences in the sizes of the Di-I labeled patches in the normal and 5,7 DHTtreated animals. Scale bar, $500 \mu \mathrm{m}$. $\mathrm{mm}^{2}$ (Fig. $11 C$ ). This $19.3 \%$ reduction was statistically significant $(p<0.05)$.

Effects of 5,7-DHT treatment on the area of cortex devoted to the vibrissa representation

All of the results presented in the preceding subsections indicate that 5,7-DHT treatment results in a reduction of the size of the patches of thalamocortical afferents or $\mathrm{CO}$ activity representing the mystacial vibrissae and that this occurs without a corresponding shrinkage of the brain or cortex or a reduction in the size of the subcortical representations of the mystacial vibrissa follicles. Analysis of distances between the centers of patches of thalamocortical afferents labeled by staining for $\mathrm{AChE}$ or thalamic application of Di-I (Fig. 12) demonstrated further that neonatal 5,7-DHT treatment did not significantly reduce the size of the total cortical area devoted to the representation of 

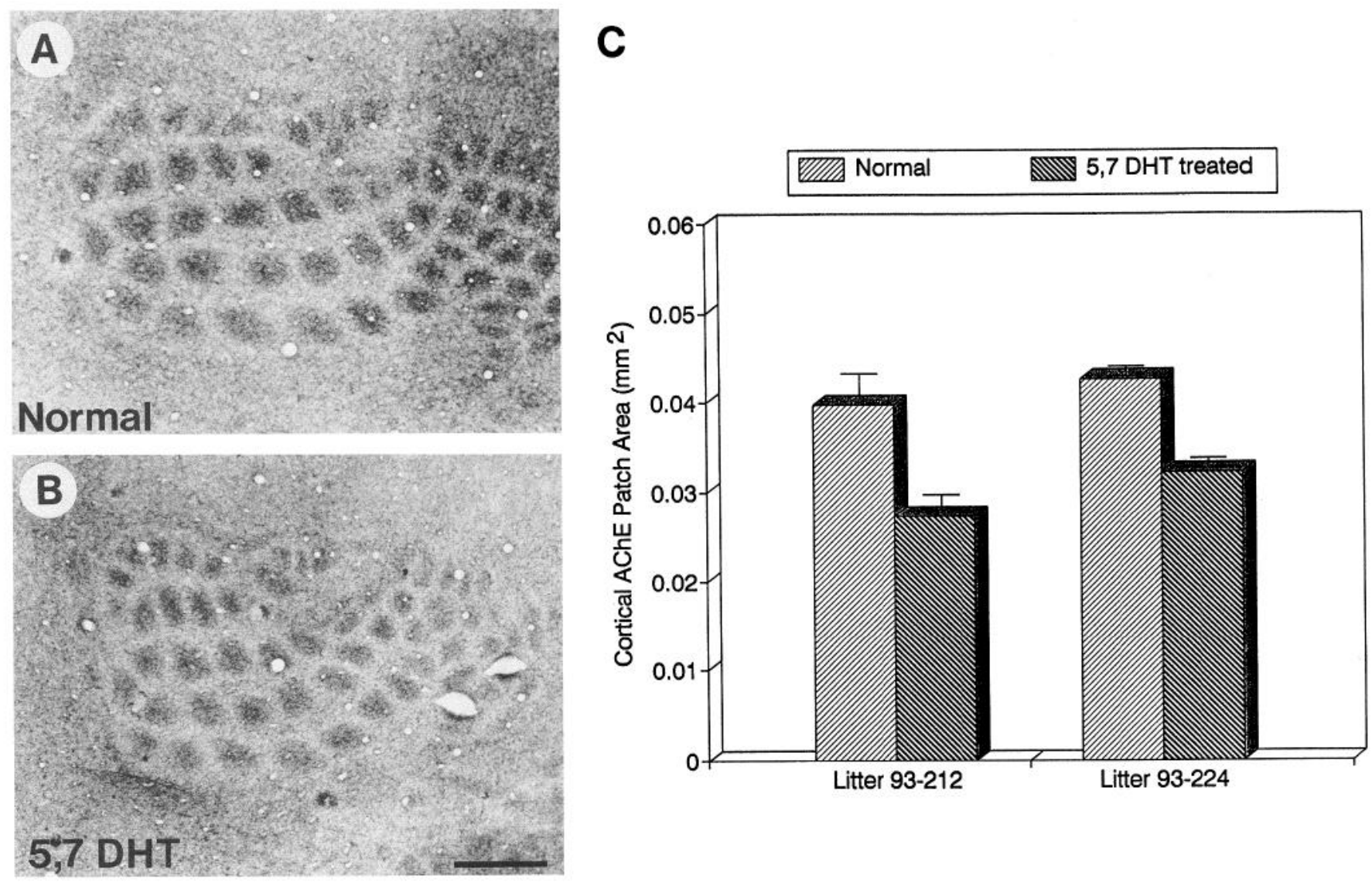

Figure 8. $A$ and $B$, Low-power photomicrographs of tangential sections through layer IV of S-I stained for AChE. $A$ is from a P-6 control, and $B$ is from a littermate that received a 5,7-DHT injection. $C$ is a histogram showing the results of cortical AChE patch measurements taken from two litters killed on P-6. Each bar represents the average for all of the patches measured in either the control or the 5,7-DHT injected animals. The differences between the treated and untreated animals in each litter were statistically significant $(p<0.05)$. Scale bar, $500 \mu \mathrm{m}$.

the long mystacial vibrissae. Importantly, all of the animals included in this analysis were also included in that which showed that neonatal 5,7-DHT treatment reduced the size of the cortical AChE patches corresponding to the vibrissae.

\section{Discussion}

The present results indicate that depletion of 5-HT from the developing cortex by administration of 5,7-DHT on the day of birth produces a significant and maintained reduction in the size of the patches that comprise the cortical representation of the long mystacial vibrissae. This decrease occurs without any corresponding changes in the weight of the brain or cortex, in the overall area of the cortex devoted to the vibrissa representation, or in the CO-reactive patches corresponding to the vibrissae in the ventrobasal thalamus.

\section{Technical limitations}

Before relating the present results to those of previous studies, it is important to acknowledge several important limitations of this study. First, we were unable to evaluate the effects of 5-HT depletion on the cytoarchitectonic units representing the vibrissae, the barrels. In the rat's somatosensory cortex, these aggregates of cells are much less well defined than in the mouse and we therefore restricted our measurements to patches of thalamocortical afferents in the perinatal animals and $\mathrm{CO}$-stained patches in the adult rats. We did attempt to carry out a parallel series of experiments in mice, but were unable to obtain $>60 \%$ depletions of 5-HT in the cortices of these animals with the combination of 5,7-DHT and DMI (see Osterheld-Haas, 1994, for comparable data). In mice depleted to this extent, somatotopically distributed 5-HT-positive could still be seen in immunostained cortical sections.

One puzzling aspect of our results apparent from examination of the data presented in Figure 6 is that there was considerable variability in the size of vibrissa-related patches in animals from different litters. This effect was not significantly related to brain weight $(r=0.11, p>0.05)$. One other source of variability that should be acknowledged is the difference in the labeling efficiency of the three methods employed to visualize patches of vibrissa-related thalamocortical afferents in perinatal rats. The patches labeled by application of Di-I to the thalamic radiations were larger than those labeled by injection of Di-I into the thalamus and these were larger than those labeled by staining for AChE. The smaller size of the AChE-stained patches is readily explained by the tissue shrinkage associated with histochemical processing. The larger size of patches labeled by application of Di-I to the thalamic radiations versus those labeled by thalamic injection of the same tracer is most likely due to the more complete labeling that might be expected after very large tracer deposits placed very close to the target analyzed. It is important to note that these differences did not influence our 
analysis since all comparisons were among cortical patches labeled by the same method.

\section{Relationship of present results to those from previous studies}

One important aspect of the present results agrees well with the prior findings of Daugherty and Haring (1989) and Blue et al. (1991). Results from both of those studies and the present report are in agreement in that cortical 5-HT depletion had no effect upon the somatotopic organization of the vibrissa representation in the developing cortex. However, the present results differ from those provided by Daughtery and Haring (1989) in that we observed significant reductions in the cross-sectional areas of the patches of Di-I-labeled thalamocortical fibers (in perinatal rats) and CO reactivity (in adult animals) while Daughtery and Haring (1989) did not report any such change in rats killed at $20 \mathrm{~d}$ of age.

One potential source of the difference between the present findings and those of Daughtery and Haring (1989) is the difference in the degree of cortical 5-HT depletion achieved in the two studies. Daughtery and Haring (1989) achieved a 65\% loss of 5-HT from cortex at $3 \mathrm{~d}$ after their PCA injections, but levels of this amine were reduced by only $25 \%$ in adulthood, the time at which all of their evaluations of cortical morphology were carried out. In the present study, the average 5-HT depletion on $\mathrm{P}-6$ was $85.4 \%$ and that in adulthood was $72.5 \%$.

\section{Potential mechanisms underlying the effect of 5-HT on the developing cortex}

There are a number of ways in which neonatal depletion of 5-HT might reduce the size of the patches of thalamocortical afferents corresponding to the mystacial vibrissae. It is possible that 5,7-DHT treatment reduces the number of thalamocortical fibers that contribute to a given cortical patch. We do not believe that this is the case since the size of the CO-reactive patches corresponding to the vibrissae in the thalami of the 5,7-DHTtreated animals were normal. Moreover, preliminary counts of neurons in the ventrobasal complex of one normal and one 5,7DHT-treated rat, each killed on P-6, indicate that 5,7-DHT treatment did not reduce thalamic cell number (C. A. BennettClarke, unpublished observations).

It is also possible that 5,7-DHT treatment reduced the size of the terminal arbors of individual thalamocortical fibers. This possibility might be viewed as consistent with the results of in vitro studies that have shown that increasing concentrations of 5-HT enhance neuropil formation and synaptic development in the growing cortex (e.g., Chubakov et al., 1986). The suggestion of a direct positive effect of 5-HT upon axonal growth seems somewhat surprising in view of the work of Kater and his colleagues (Haydon et al., 1984; Haydon et al., 1987; McCobb et al., 1988a,b). They demonstrated that addition of 5-HT to the culture medium surrounding growing neurites from Helisoma neurons caused an immediate cessation of their elongation. However, it must be noted that the effects of 5-HT in this system were quite specific. 5-HT consistently arrestcd ncuritc clongation for identified neurons B19, P1, and P5, but not for cells B4 and B5 (McCobb et al., 1988b). More recently, Goldberg and Kater (1989) showed that depletion of 5-HT in developing $\mathrm{Hel}$ isoma in vivo by administration of 5,7-DHT also altered the development of B-19. Baker et al. (1993) have also demonstrated that depletion of 5-HT in the snail Achatina fulica results in axonal sprouting by buccal ganglion neurons.

It is also possible that the 5,7-DHT-induced reduction in
A

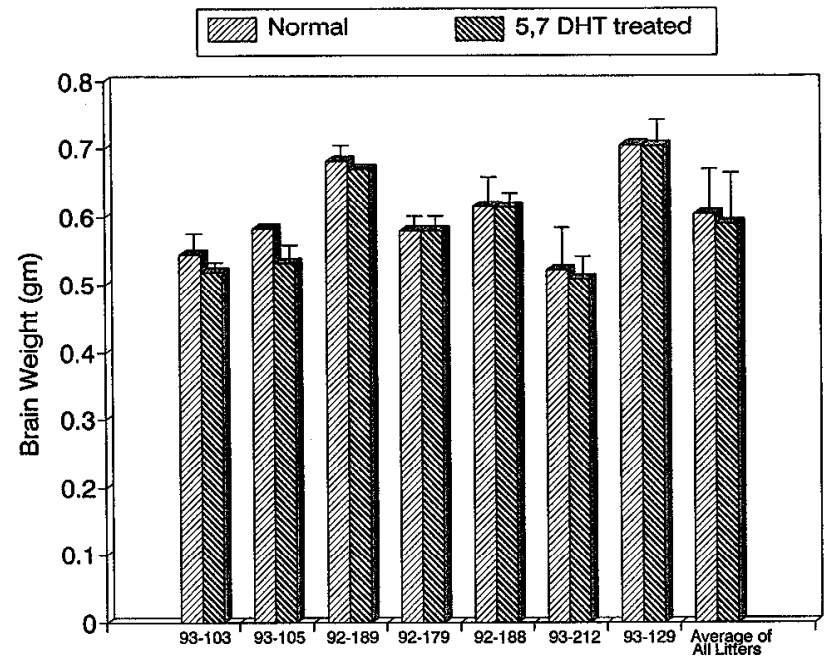

B

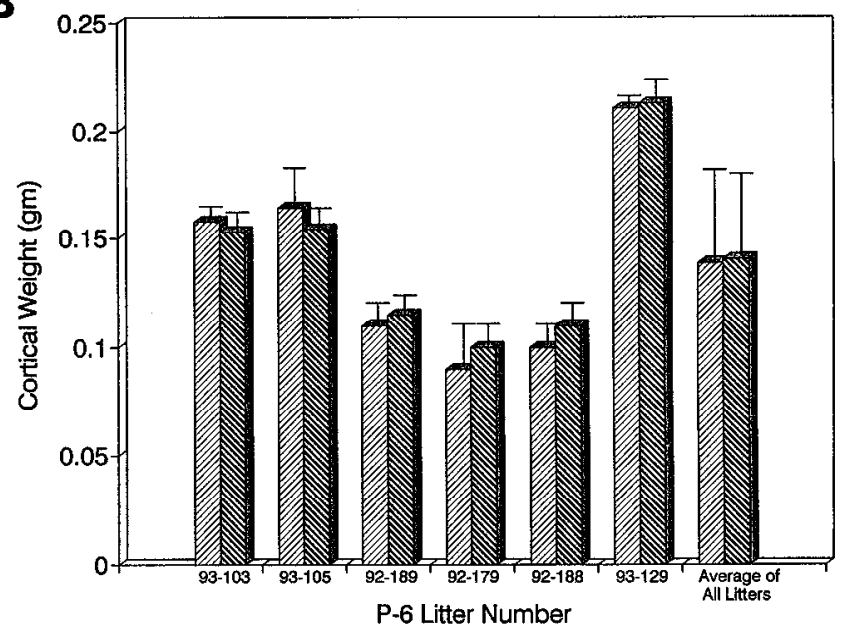

Figure 9. A shows the brain weights (mean $+\mathrm{SD}$ ) for animals from many of the litters that provided the data for this study. $B$ shows the cortical weights for several of these animals. There were no statistically significant differences between the results from the normal and 5,7DHT-treated animals.

5-HT concentration in the developing cortex influenced the size of individual thalamocortical axon arbors indirectly, perhaps by changing the normal operation of activity-dependent processes. There is strong evidence from many portions of the mature nervous system that $5-\mathrm{HT}$ acting at the $5-\mathrm{HT}_{1 \mathrm{~B}}$ receptor has very strong presynaptic inhibitory effects (Bobker and Williams, 1989, 1990a; Wu et al., 1991; Tan and Miletic, 1992; Huang et al., 1993). Shi et al. (1993) have also shown that 5-HT has presynaptic inhibitory effects in the developing somatosensory cortex and provided additional evidence indicating that these effects are mediated by the $5-\mathrm{HT}_{1 \mathrm{~B}}$ receptor. In addition, Leslie et al. (1992) used autoradiographic techniques to show that $5-\mathrm{HT}_{1 \mathrm{~B}}$ receptors assume a pattern that exactly matches that of 5-HT-immunorcactivc fibcrs and thalamocortical afferents during the first 2 weeks of development and Bennett-Clarke et al. (1993) demonstrated further that these receptors are located on the terminals of thalamocortical axons.

If a change in the normal operation of activity-dependent processes underlies the morphological changes observed in the present study, our results might be viewed as reflecting a process similar to that suggested by the results of Cline et al. (1987) and Cline and Constantine-Paton (1990). They showed that inter- 

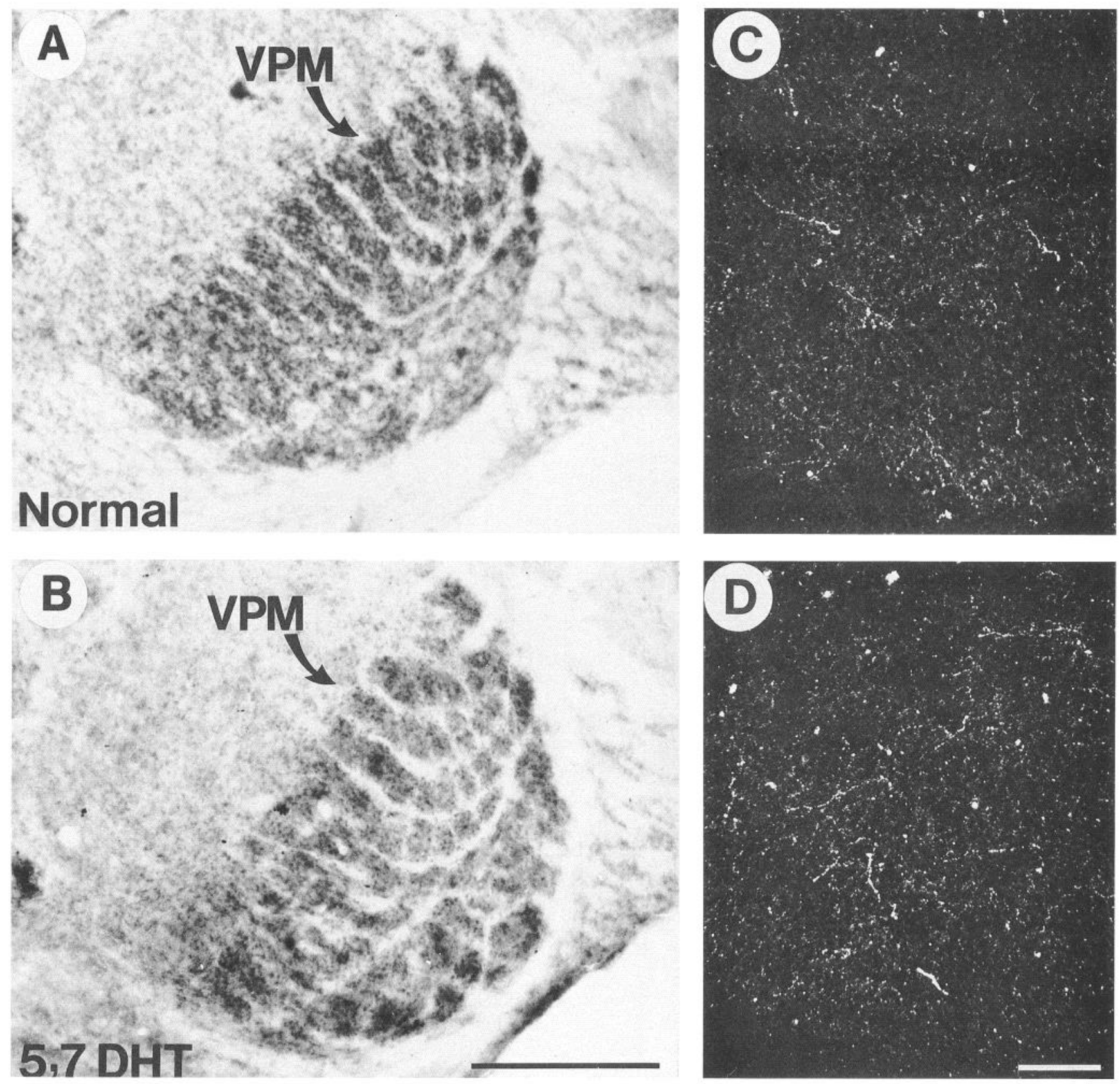

Figure 10. $A$ and $B$ show CO-stained coronal sections through VPM of a normal $(A)$ and a 5,7-DHT-treated rat $(B)$. Note the patches corresponding to the vibrissae. $C$ and $D$ are adjacent sections stained for CO that have been processed for 5-HT. Note the similarity in the densities of immunoreactivity in the two animals. Scale bars: $A$ and $B, 250 \mu \mathrm{m} ; C$ and $D, 100 \mu \mathrm{m}$.

ference with retinotectal activity in "three-eyed" frogs by application of NMDA receptor antagonists disrupted the segregation of axons into eye-specific domains, but that the application of exogenous NMDA actually sharpened boundaries between the tectal regions innervated by one or the other eye and reduced the size and branching of retinotectal axons. Cline and Constantine-Paton (1990) suggested that the smaller size and decreased branching of retinotectal axons in NMDA-treated tecta reflected augmentation of the normal process in which coactive axon branches are selectively stabilized. It seems reasonable to suggest that the same sort of augmentation of activity-dependent processes might occur when 5-HT is depleted from the devel- oping cortex. Direct comparison of the present results with those of Constantine-Paton and associates awaits analysis of single thalamocortical axons from 5,7-DHT-treated rats.

The suggestion that the effects of 5,7-DHT upon the development of thalamocortical axons result from removal of 5-HTmediated presynaptic inhibition and enhancement of activitydependent axonal sorting processes seems difficult to reconcile with observations that direct manipulations of cortical activity have no significant effects upon normal thalamocortical development assessed using methods similar to those employed in this study. Chiaia et al. (1992) showed that blockade of cortical activity with TTX did not reduce the size of the patches of 

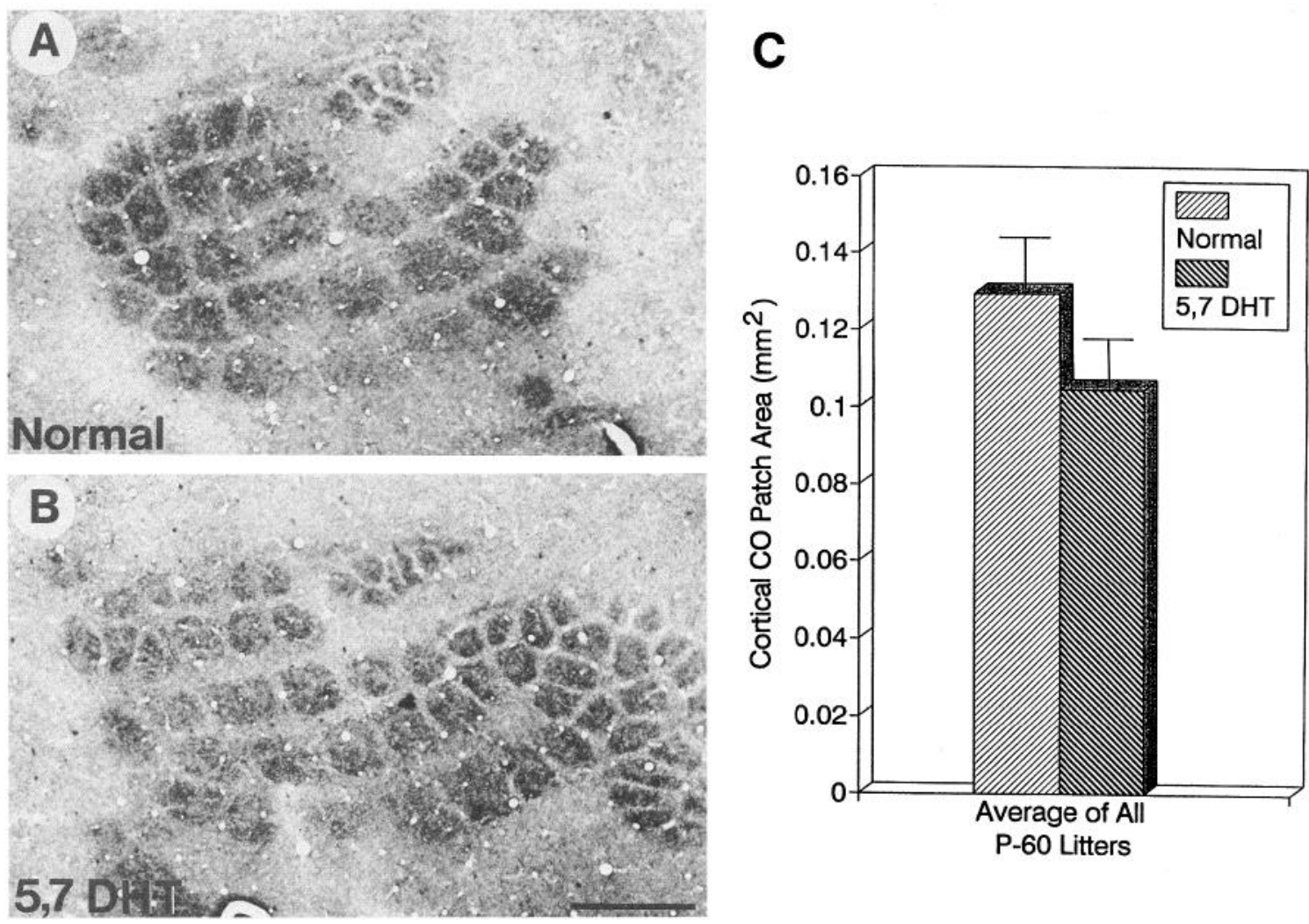

Figure 11. $A$ and $B$ are low-power bright-field photomicrographs of tangential sections through lamina IV of parietal cortex of one normal adult rat $(A)$ and a littermate that received a subcutaneous injection of 5,7-DHT on the day of birth $(B)$. Cortical aggregates related to vibrissae have been visualized by staining for CO. $C$ shows areas (mean $+\mathrm{SD}$ ) of CO-stained cortical barrels of normal and 5,7-DHT treated adult rats. The difference between the normal and 5,7-DHT-treated animals was statistically significant $(p<0.05)$. Scale bar, $1 \mathrm{~mm}$.

thalamocortical afferents labeled with Di-I and Schlaggar et al. (1993) have reported similar results from rats in which NMDA receptors were blocked in the developing cortex with APV and cortical organization was evaluated by staining for AChE.

While it may difficult to relate the results of Chiaia et al. (1992) and those of Schlaggar et al. (1993) with those from the present study, it is worth pointing out the different effects of the manipulations employed in the three studies on cortical activity. Application of TTX should block most pre- and postsynaptic activity in the developing cortex (see Katz and Yuste, 1991, for an exception to this generalization). Application of APV should attenuate all postsynaptic activation associated with glutamate and block that associated with activation of the NMDA receptor. In contrast, the main effect of 5-HT depletion during development should be enhancement of thalamocortical transmission (Shi et al., 1993). Thus, administration of 5,7-DHT at birth should increase cortical activity while treatment with either TTX or APV should reduce it. This distinction is important since available data (Armstrong-James, 1975) suggest that the spontaneous activity level in the developing primary somatosensory cortex is low and stimulus-evoked responses are weak. It thus seems reasonable to suggest that blockade of activity in the developing somatosensory cortex of the rat has no effect on the morphometry of the vibrissa representation because activities levels during the period when this pattern is forming are already quite low. The potential of 5,7-DHT treatment to increase thalamocortical transmission and enhance cortical activ- ity and its effect on the organization of thalamocortical afferents are consistent with the possibility that activity can influence normal thalamocortical development in the rat's somatosensory system, but perhaps only under unusual conditions such as those created by pharmacologic manipulations.

The present demonstration of modulation of the growth of a specific thalamocortical representation without any overall change in cortical mass appears inconsistent with the view regarding somatosensory cortical growth put forward by Riddle et al. $(1992,1993)$. These investigators showed that different portions of the somatosensory cortical representation in rat, as demonstrated by $\mathrm{CO}$ staining, underwent considerable differential growth. In particular, the representation of the mystacial vibrissa follicles demonstrated a very substantial increase in size while that shown for the dysgranular cortex was significantly smaller. Riddle et al. (1992) suggested that this differential growth might be the result of differing activity levels in these two regions. The results provided by Chiaia et al. (1992), Henderson et al. (1992), and Schlaggar et al. (1993) would suggest that activity that can be blocked by TTX may not be important for the differential postnatal growth of the representation of the vibrissa follicles. The present results extend these observations by showing that another manipulation that should have profound effects upon cortical activity reduces the size of the cortical representations of individual vibrissa follicles without changing the overall size of the cortical region devoted to the representation of the vibrissae. 

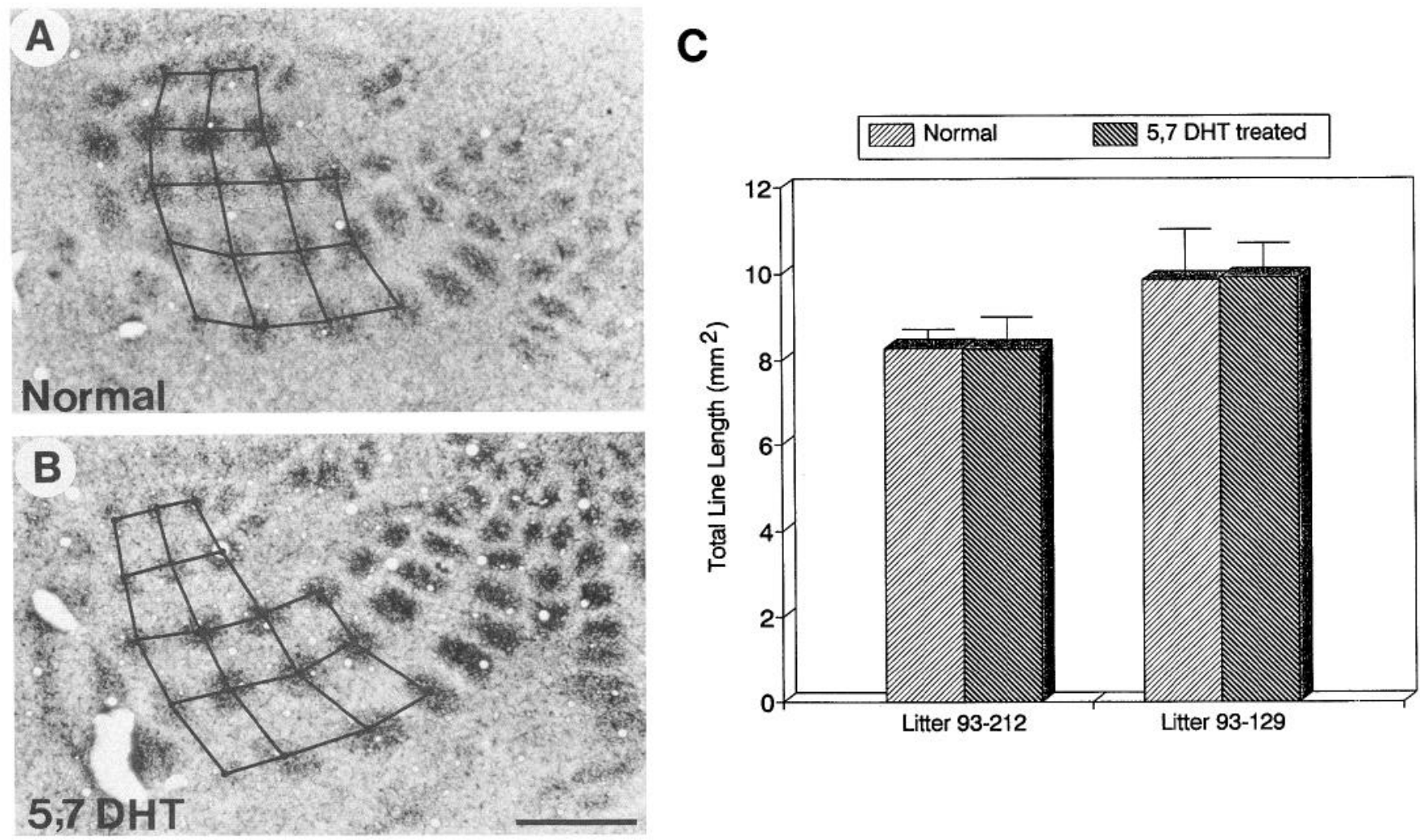

Figure 12. $A$ and $B$ are AChE-stained tangential sections from normal $(A)$ and 5,7-DHT-treated $(B)$ littermates killed at P-6. The lines over each section connect the centers of the patches corresponding to the caudal four vibrissae in each row that are visible in these sections. The left pair of bars in $C$ shows a comparison of the summed length (mean $+\mathrm{SD}$ ) of the line segments connecting the centers of the patches analyzed in normal and 5,7-DHT-treated rats from one litter in which AChE was used to visualize the terminations of thalamocortical fibers. The right pair of bars shows results from a second litter in which DiI was applied to VPM to visualize thalamocortical axons. Line segments were established and measured as described for the previous litter. Scale bar, $500 \mu \mathrm{m}$.

\section{References}

Armstrong-James M (1975) The functional status and columnar organization of single cells responding to cutaneous stimulation in neonatal rat somatosensory cortex S1. J Physiol (Lond) 246:501-538.

Baker MW, Vohra MM, Croll RP (1993) Serotonin depletors 5,7dihydroxytryptamine and $p$-chlorophenylalanine, cause sprouting in the CNS of the adult snail. Brain Res 623:311-315.

Bennett-Clarke CA, Chiaia NL, Crissman RS, Rhoades RW (1991) The source of the transient serotonergic input to the developing visual and somatosensory cortices in rat. Neuroscience 43:163-183.

Bennett-Clarke CA, Leslie MJ, Chiaia NL, Rhoades RW (1993) Serotonin $1 \mathrm{~B}$ receptors in the developing somatosensory and visual cortices are located on the thalamocortical axons. Proc Natl Acad Sci USA 90:153-157.

Blue ME, Erzurumlu RS, Jhaveri S (1991) A comparison of pattern formation by thalamocortical and serotonergic afferents in the rat barrel field cortex. Cereb Cortex 1:380-389.

Bobker DH, Williams JT (1989) Serotonin agonists inhibit synaptic potentials in the rat locus ceruleus in vitro via 5-hydroxytryptamine $\mathrm{A}_{1 \mathrm{~A}}$ and 5-hydroxytryptamine ${ }_{1 \mathrm{~B}}$ receptors. J Pharmacol Exp Ther 250:3743.

Bobker DH, Williams JT 1990) Serotonin-mediated inhibitory postsynaptic potential in guinea-pig propositus hypoglossi and feedback inhibition by serotonin. J Physiol (Lond) 422:447-462.

Chiaia NL, Fish SE, Bauer WR, Bennett-Clarke CA, Rhoades RW (1992) Postnatal blockade of cortical activity by tetrodotoxin does not disrupt the formation of vibrissa-related patterns in the rat's somatosensory cortex. Dev Brain Res 66:244-250.

Chubakov AR, Gromova EA, Konovalov GV, Sarkisova EF, Chumasov EI (1986) The effects of serotonin on the morphofunctional development of rat cerebral neocortex in tissue culture. Brain Res 369:285-297.
Cline HT, Constantine-Paton M (1990) NMDA receptor agonist and antagonists alter retinal ganglion cell arbor structure in the developing frog retinotectal projection. J Neurosci 10:1197-1216.

Cline HT, Debski E, Constantine-Paton M (1987) NMDA receptor antagonist desegregates eye-specific stripes. Proc Natl Acad Sci USA $84: 4342-4345$.

D'Amato RJ, Blue ME, Largent BL, Lynch DR, Ledbetter DJ, Molliver ME, Snyder SH (1987) Ontogeny of the serotonergic projection to rat neocortex: transient expression of a dense innervation to primary sensory areas. Proc Natl Acad Sci USA 84:4322-4326.

Daugherty JA, Haring JH (1989) Effects of neonatal serotonin depletion upon development of rat somatosensory cortex. Soc Neurosci Abstr 15:1050.

Fujimiya M, Kimura H, Maeda T (1986) Postnatal development of serotonin nerve fibers in the somatosensory cortex of mice studied by immunohistochemistry. J Comp Neurol 246:191-201.

Ghosh A, Antonini A, McConnell SK, Shatz CJ (1990) Requirement of subplate neurons in the formation of thalamocortical connections. Nature 347:179-181.

Goldberg JI, Kater SB (1989) Expression and function of the neurotransmitter serotonin during development of Helisoma nervous system. Dev Biol 131:483-495.

Haydon PG, McCobb DP, Kater SB (1984) Serotonin selectively inhibits growth cone motility and synaptogenesis of specific identified neurons. Science 226:561-564.

Haydon PG, McCobb DP, Kater SB (1987) The regulation of neurite outgrowth, growth cone motility and electrical synaptogenesis by serotonin. J Neurobiol 18:197-215.

Henderson TA, Woolsey TA, Jacquin MF (1992) role of postnatal primary afferent impulse activity in central trigeminal pattern formation in the rat. Brain Res, in press.

Huang X, Mooney RD, Rhoades RW (1993) Effects of serotonin (5HT) upon retinotectal, corticotectal, and glutamate-induced activity in the superior colliculus of the hamster. J Neurophysiol, in press. 
Katz LC, Yuste R (1991) Spontaneous calcium transients in developing neocortical neurons. Soc Neurosci Abstr 17:1470.

Killackey HP, Jacquin MF, Rhoades RW (1990) Development of somatosensory system structures. In: Development of sensory systems in mammals (Coleman JR, ed), pp 403-429. New York: Wiley.

Krisst DA (1979) Somatosensory cortex: acetylcholinesterase staining of barrel neuropil in the rat. Neurosci Lett 12:177-182.

Lauder JM (1983) Hormonal and humoral influences on brain development. Psychoneuroendocrinology 8:121-155.

Lauder JM, Krebs H (1978) Serotonin as a differentiation signal in early neurogenesis. Dev Neurosci 1:15-30.

Leslie MJ, Bennett-Clarke CA, Rhoades RW (1992) Serotonin 1B receptors form a transient vibrissa-related pattern in the primary somatosensory cortex of the developing rat. Dev Brain Res 69:143148.

Lidov HGW, Molliver ME (1982) An immunohistochemical study of serotonin neuron development in the rat: ascending pathways and terminal fields. Brain Res Bull 8:389-430.

McCobb DP, Cohan CS, Connor JA, Kater SB (1988a) Interactive effect of serotonin and acetylcholine on neurite elongation. Neuron $1: 377-385$.

McCobb DP, Haydon PG, Kater SB (1988b) Dopamine and serotonin inhibition of neurite elongation of different identified neurons. J Neurosci Res 19:19-26.

Osterheld-Haas MC, Van der Loos H, Hornung J-P (1994) Monoaminergic afferents to cortex modulate structural plasticity in the barrelfield of the mouse. Dev Brain Res 77:189-202.

Rhoades RW, Bennett-Clarke CA, Chiaia NL, White FA, MacDonald GJ, Haring JH, Jacquin MF (1990) Development and lesion induced reorganization of the cortical representation of the rat's body surface as revealed by immunocytochemistry for serotonin. J Comp Neurol 293:190-207.
Riddle D, Richards A, Zsuppan F, Purves D (1992) Growth of the rat somatic sensory cortex and its constituent parts during postnatal development. J Neurosci 12:3509-3524.

Robertson RT, Hanes MA, Yu J (1988) Investigations of the origins of transient acetylcholinesterase activity in developing rat visual cortex. Dev Brain Res 41:1-23.

Schlaggar BL, Fox K, O'Leary DDM (1993) Postsynaptic control of plasticity in the developing cortex. Nature 364:623-626.

Shi M-Y, Mooney RD, Bennett-Clarke CA, Rhoades RW (1993) Effects of serotonin (SHT) on somatosensory cortex of neonatal rats in vitro. Soc Neurosci Abstr 19:1094.

Steindler DA, Cooper NGF, Schachner M (1989) Boundaries defined by adhesion molecules during development of the cerebral cortex: the $\mathrm{J} 1 /$ tenascin glycoprotein in the mouse somatosensory cortex barrel field. Dev Biol 131:243-260.

Tan H, Miletic V (1992) Diverse actions of 5-hydroxytryptamine on frog dorsal horn neurons in vitro. Neuroscience 49:913-923.

Van der Loos H, Dorfl J (1978) Does the skin tell the somatosensory cortex how to construct a map of the periphery. Neurosci Lett 7:2330.

Wong-Riley MTT (1979) Changes in the visual system of monocularly sutured or enucleated cats demonstrable with cytochrome oxidase histochemistry. Brain Res 171:11-28.

Woolsey TA (1990) Peripheral alteration and somatosensory development. In: Development of sensory systems in mammals (Coleman JR, ed), pp 461-516. New York: Wiley.

Wu SY, Wang MY, Dun NJ (1991) Serotonin via presynaptic 5-HT, receptors attenuates synaptic transmission to immature rat motoneurons in vitro. Brain Res 554:111-121. 